\title{
Authentically Phosphorylated $\alpha$-Synuclein at Ser129 Accelerates Neurodegeneration in a Rat Model of Familial Parkinson's Disease
}

\author{
Hiroyasu Sato, Shigeki Arawaka, Susumu Hara, Shingo Fukushima, Kaori Koga, Shingo Koyama, and Takeo Kato \\ Department of Neurology, Hematology, Metabolism, Endocrinology and Diabetology, Yamagata University Faculty of Medicine, Yamagata 990-9585, Japan
}

Parkinson's disease (PD) is characterized by the loss of dopaminergic neurons in the substantia nigra (SN) and the appearance of fibrillar aggregates of insoluble $\alpha$-synuclein ( $\alpha$-syn) called Lewy bodies (LBs). Approximately $90 \%$ of $\alpha$-syn deposited in LBs is phosphorylated at serine 129 (Ser129). In contrast, only $4 \%$ of total $\alpha$-syn is phosphorylated in normal brain, suggesting that accumulation of Ser129phosphorylated $\alpha$-syn is involved in the pathogenesis of PD. However, the role of Ser 129 phosphorylation in $\alpha$-syn neurotoxicity remains unclear. In this study, we coexpressed familial PD-linked A53T $\alpha$-syn and G-protein-coupled receptor kinase 6 (GRK6) in the rat SN pars compacta using recombinant adeno-associated virus 2. Coexpression of these proteins yielded abundant Ser129-phosphorylated $\alpha$-syn and significantly exacerbated degeneration of dopaminergic neurons when compared with coexpression of A53T $\alpha$-syn and GFP. Immunohistochemical analysis revealed that Ser129-phosphorylated $\alpha$-syn was preferentially distributed to swollen neurites. However, biochemical analysis showed that the increased expression of Ser129-phosphorylated $\alpha$-syn did not promote accumulation of detergentinsoluble $\alpha$-syn. Coexpression of catalytically inactive K215R mutant GRK6 failed to accelerate A53T $\alpha$-syn-induced degeneration. Furthermore, introducing a phosphorylation-incompetent mutation, S129A, into A53T $\alpha$-syn did not alter the pace of degeneration, even when GRK6 was coexpressed. Our study demonstrates that authentically Ser129-phosphorylated $\alpha$-syn accelerates A53T $\alpha$-syn neurotoxicity without the formation of detergent-insoluble $\alpha$-syn, and suggests that the degenerative process could be constrained by inhibiting the kinase that phosphorylates $\alpha$-syn at Ser129.

\section{Introduction}

Parkinson's disease (PD) is characterized by the loss of dopaminergic neurons in the substantia nigra pars compacta $(\mathrm{SNc})$ and the presence of intracytoplasmic inclusions called Lewy bodies (LBs) and Lewy neurites (LNs). Missense mutations (A53T, A30P, and E46K) of the $\alpha$-synuclein ( $\alpha$-syn) gene and multiplication of the $\alpha$-syn gene locus cause autosomal dominantly inherited forms of PD (Eriksen et al., 2003). $\alpha$-syn is also a major component of the fibrillar aggregates in LBs and LNs in sporadic PD and in dementia with Lewy bodies (DLB) (Spillantini et al., 1997). The process of $\alpha$-syn aggregation, eventually leading to the formation of LBs and LNs, appears to be a major contributor to neurodegeneration in PD (Eriksen et al., 2003; Lee and Trojanowski, 2006).

Immunohistochemical and biochemical studies have shown that $\sim 90 \%$ of $\alpha$-syn deposited in LBs is phosphorylated at serine

\footnotetext{
Received July 25, 2011; revised 0ct. 4, 2011; accepted 0ct. 5, 2011.

Author contributions: H.S. and S.A. designed research; H.S., S.A., S.H., S.F., K.K., and S.K. performed research; H.S., S.F., and K.K. analyzed data; H.S., S.A., and T.K. wrote the paper.

This work was supported in part by a Grant-in-Aid from the Global Centers of Excellence Program (F03) of the Japan Society for the Promotion of Science (T.K.) and a Grant-in-Aid for Scientific Research (C) (No. 23591230) from the Ministry of Education, Culture, Sports, Science, and Technology of Japan (S.A.).

The authors declare no competing financial interests.

Correspondence should be addressed to Shigeki Arawaka, Department of Neurology, Hematology, Metabolism, Endocrinology and Diabetology, Yamagata University Faculty of Medicine, 2-2-2 lida-nishi, Yamagata, Japan 9909585. E-mail: arawaka@med.id.yamagata-u.ac.jp.

DOI:10.1523/JNEUROSCI.3967-11.2011

Copyright $\odot 2011$ the authors $\quad 0270-6474 / 11 / 3116884-11 \$ 15.00 / 0$
}

129 (Ser129) (Fujiwara et al., 2002; Anderson et al., 2006). In contrast, the proportion of phosphorylated $\alpha$-syn in normal brain is only $4 \%$ of total $\alpha$-syn (which includes nonphosphorylated and phosphorylated forms), suggesting that accumulation of Ser 129-phosphorylated $\alpha$-syn is involved in the formation of LBs and neurodegeneration associated with PD (Fujiwara et al., 2002). In a transgenic Drosophila model of PD, coexpression of $\alpha$-syn and a Drosophila homolog of G-protein-coupled receptor kinase 2 (GRK2) yielded Ser129-phosphorylated $\alpha$-syn and enhanced $\alpha$-syn neurotoxicity (Chen and Feany, 2005). However, in rat recombinant adeno-associated virus (rAAV)-based models of PD, the expression of phosphorylation-mimic S129D mutant $\alpha$-syn did not display toxicity toward dopaminergic neurons (Gorbatyuk et al., 2008; Azeredo da Silveira et al., 2009; McFarland et al., 2009). There has been a lack of consistency between fly and rat models on the effects of $\alpha$-syn phosphorylation (Cookson, 2009). Earlier in vitro studies demonstrated that the S129D $\alpha$-syn could not reproduce the structural and aggregational properties of authentically Ser129-phosphorylated $\alpha$-syn (Paleologou et al., 2008). In addition, the degradation pathway of S129D $\alpha$-syn was different from that of Ser129-phosphorylated $\alpha$-syn in SH-SY5Y cells (Machiya et al., 2010). These data cast doubt on the validity of using S129D mutant $\alpha$-syn to assess toxicity of Ser129-phosphorylated $\alpha$-syn.

To investigate the role of Ser129 phosphorylation in $\alpha$-syninduced neurodegeneration, we focused on authentic (kinasemediated) phosphorylation at this residue. Various kinases, 
including casein kinases (CKs) (Okochi et al., 2000), GRKs (Pronin et al., 2000), and Polo-like kinases (Inglis et al., 2009; Mbefo et al., 2010), phosphorylate $\alpha$-syn at Ser129. We used GRK6 to generate Ser129-phosphorylated $\alpha$-syn in the rat SNc for the following reasons: (1) GRK6 is known to be endogenously expressed in rat dopaminergic neurons (Fehr et al., 1997; Erdtmann-Vourliotis et al., 2001); (2) siRNA-mediated knockdown experiments show that endogenous GRK6 contributes to Ser129 phosphorylation of $\alpha$-syn in HEK293 cells (Sakamoto et al., 2009); and (3) substituting arginine for lysine at position 215 (K215R) in GRK6 results in a catalytically inactive enzyme in cells (Willets et al., 2002). Here, we report that authentically Ser129phosphorylated $\alpha$-syn accelerates A53T $\alpha$-syn-induced neurodegeneration, and that this effect can be abolished by inactivating the kinase.

\section{Materials and Methods}

Recombinant adeno-associated virus 2 preparation. We initially constructed the pAAV-CAG-(woodchuck hepatitis virus post-transcriptional regulatory element) vector (Donello et al., 1996; Fitzsimons et al., 2002). The transgene of interest, such as human A53T $\alpha$-syn, A53T/S129A $\alpha$-syn, human wildtype (WT) GRK6, catalytically inactive K215R GRK6 and EGFP, was inserted into the vector as driven by the CAG promoter (Niwa et al., 1991) containing the chicken $\beta$-actin promoter. Nucleotide sequences of the transgenes were confirmed by DNA sequencing. rAAV2 was purified by iodixanol step gradients and heparin-agarose column chromatography as described previously (Zolotukhin et al., 1999, 2002). The viral titers were determined by quantitative real-time PCR using a set of primers for WPRE (Ciron et al., 2009).

Stereotaxic rAAV2 injections. Nine- to ten-week-old Sprague Dawley rats were used. These experiments had been approved by the Animal Subjects Committee of Yamagata University. Before surgery, the anesthetized rats were placed in a stereotaxic frame (Narishige). All injections were made unilaterally into the left $\mathrm{SN}$ at the following coordinates: 5.2 $\mathrm{mm}$ posterior to and $2.0 \mathrm{~mm}$ left of bregma, $7.7 \mathrm{~mm}$ ventral to dura. Four microliters of viral solution containing two different rAAV2 were coinjected per site with a 22 gauge needle and a $25 \mu$ l Hamilton syringe at a speed of $250 \mathrm{nl} / \mathrm{min}$ using microsyringe pump (World Precision Instruments). In rAAV-A53T $\alpha$-syn and rAAV-A53T/S129A $\alpha$-syn, $1.4 \times 10^{10}$ genome copies were injected, while $1.7 \times 10^{10}$ genome copies were injected into rAAV-WT GRK6 and rAAV-K215R GRK6. After injection, the needle was kept in place for additional $10 \mathrm{~min}$ before withdrawal.

Primary antibodies. The following primary antibodies were used: antityrosine hydroxylase antibody (AB152, Millipore), anti-HuC/D antibody (16A11, Invitrogen), anti-human $\alpha$-syn antibody (LB509, Zymed Laboratories), anti- $\alpha$-syn antibody (Syn-1, it recognizes both rat and human $\alpha$-syn; BD Transduction Laboratories), anti-Ser129-phosphorylated $\alpha$-syn monoclonal antibody (psyn\#64, Wako), anti-Ser129-phosphorylated $\alpha$-syn polyclonal antibody (EYPSYN-01, courtesy of Eisai), anti-GRK6 antibody (sc-566, Santa Cruz Biotechnology), anti-dopamine transporter antibody (sc-1433, Santa Cruz Biotechnology), anti-GFP antibody (A11122, Invitrogen), and anti-GAPDH antibody (ab8245, Abcam).

Immunohistochemistry. Under diethyl ether anesthesia, the animals were transcardially perfused with physiological saline followed by $4 \%$ paraformaldehyde (PFA)/PBS (10 mm phosphate, $137 \mathrm{~mm} \mathrm{NaCl}, 2.7 \mathrm{~mm}$ $\mathrm{KCl}$ ). The brains were removed and postfixed in $8 \% \mathrm{PFA} / \mathrm{PBS}$ containing $4 \%$ sucrose for $24 \mathrm{~h}$. The brains were equilibrated stepwise with $7.5 \%$, $15 \%$, and $30 \%$ sucrose. The brains were serially sectioned on a freezing microtome at $30 \mu \mathrm{m}$ in the coronal plane and serially collected into 10 wells of a 12-well plate. In each well, the sections were regularly spaced $300 \mu \mathrm{m}$ apart from each other. Immunohistochemical stainings were performed on free-floating sections. The sections were permeabilized with $0.1 \%$ Triton X-100/PBS for $10 \mathrm{~min}$ and treated with $0.3 \%$ hydrogen peroxide for $5 \mathrm{~min}$. After blocking in 3\% normal goat or horse serum for $30 \mathrm{~min}$, the sections were incubated with the primary antibody with gentle shaking at $4^{\circ} \mathrm{C}$ overnight. After washing, the sections were incubated with the appropriate biotinylated secondary antibody for $1 \mathrm{~h}$, fol- lowed by avidin-biotin-peroxidase complex (Vector Laboratories) for $1 \mathrm{~h}$. The sections were visualized using 3,3-diaminobenzidine. For single immunofluorescence labeling, Alexa568-conjugated goat anti-rabbit IgG (Invitrogen) was used as secondary antibody, and the sections were observed by an Olympus BX51 microscope (Olympus). For double immunofluorescence labeling, Alexa468-conjugated goat anti-mouse IgG and Alexa568-conjugated goat anti-rabbit IgG (Invitrogen) were used as secondary antibodies, and the sections were analyzed by an LSM Meta 510 confocal microscopy (Zeiss).

Measurement of cell number and nerve terminal density. Loss of tyrosine hydroxylase-positive $\left(\mathrm{TH}^{+}\right)$neurons was assessed by counting their number in the SNc (Sauer et al., 1995; Mandel et al., 1997). We immunostained coronal sections with anti-TH antibody. We then defined sections including anterior (approximately $-4.60 \mathrm{~mm}$ from bregma) or posterior (approximately $-6.60 \mathrm{~mm}$ from bregma) boundary of the $\mathrm{SNc}$ according to the rat brain atlas of Paxinos and Watson (2007). For each animal, we assessed six to seven sections (300 $\mu \mathrm{m}$ apart) to cover the entire $\mathrm{SNc}$ from caudal to rostral regions. Immunostained sections were viewed using the Olympus BX51 microscope with bright-field at a magnification of $200 \times$, and photomicrographs were taken with an Olympus DP70 digital camera. For each animal, $\mathrm{TH}^{+}$neurons with clear nuclei in both injected and uninjected sides on the same sections were counted by a single blinded observer. The percentage of $\mathrm{TH}^{+}$neurons relative to the uninjected control side was calculated for each animal. The data were finally expressed as mean percentage for each group.

Also, dopaminergic nerve terminal loss was assessed by semiquantifying $\mathrm{TH}^{+}$terminals in the striatum (Kirik et al., 2002). After immunostaining with the anti-TH antibody, the nearest section to the bregma was decided according to the Paxinos and Watson's atlas. Then, the optical densities of the section plus two caudal and rostral sections were quantified using ImageJ software in each animal. For statistical analysis, the data were evaluated for significance by using one-way ANOVA followed by a Bonferroni post hoc test (SPSS). The significance level was set at $p<0.05$.

Fractionation of rat midbrain tissue. At 2 weeks after injection, ventral midbrains were removed and $\alpha$-syn proteins were sequentially extracted according to the published protocol with a slight modification (Tofaris et al., 2003). Tissues were sonicated on ice in $10 \mathrm{vol}$ of TBS+ [50 mM Tris-HCl, pH 7.4, $175 \mathrm{~mm} \mathrm{NaCl}, 5$ mм EDTA, 0.1 mм PMSF, $1 \mathrm{~mm}$ $N$-ethyl-maleimide, $1 \mu \mathrm{M}$ okadaic acid (Sigma), $1 \times$ PhosSTOP (Roche Diagnostics), $1 \times$ Complete protease inhibitor cocktail (Roche Diagnostics)]. After $5 \mathrm{~min}$ of centrifugation at $1000 \times g$, the supernatant was collected and ultracentrifuged at $120,000 \times g$ for $30 \mathrm{~min}$ at $4^{\circ} \mathrm{C}$. The resulting supernatant represented the TBS soluble fraction. All subsequent centrifugation steps were performed at $120,000 \times g$ for $20 \mathrm{~min}$. The pellet was re-extracted twice with TBS + and sonicated in TBS+ containing $1 \%$ Triton X-100. After centrifugation, the resulting supernatant was collected as the TBS-insoluble/Triton X-100-soluble fraction. The pellet was re-extracted twice with TBS+ containing 1\% Triton $\mathrm{X}-100$ and sonicated in TBS + containing $1 \mathrm{~m}$ sucrose. After centrifugation, floating myelin was discarded. The pellet was then sonicated with radioimmunoprecipitation assay (RIPA) buffer (50 mM Tris- $\mathrm{HCl}, \mathrm{pH}$ 7.4, $175 \mathrm{~mm} \mathrm{NaCl}, 5 \mathrm{~mm}$ EDTA, 1\% NP-40, 0.5\% sodium deoxycholate, $0.1 \%$ SDS, $0.1 \mathrm{~mm}$ PMSF, $1 \mu \mathrm{M}$ okadaic acid, $1 \times$ PhosSTOP, $1 \times$ Complete protease inhibitor cocktail). After centrifugation, the resulting supernatant was collected as the Triton X-100-insoluble/RIPA-soluble fraction. Finally, the resultant pellet was re-extracted twice with RIPA buffer and solubilized in $8 \mathrm{M}$ urea/5\% SDS. The resultant solution represented the RIPA-insoluble/urea-soluble fraction.

Western blotting. All samples were denatured at $95^{\circ} \mathrm{C}$ for $5 \mathrm{~min}$ in Laemmli's sample buffer containing 2.5\% 2-mercaptoethanol. Equal amounts of samples were subjected to $12.5 \%$ acrylamide gel. Western blotting was performed by the methods described previously (Arawaka et al., 2006; Machiya et al., 2010). Signals were detected using a CCD camera, VersaDog 5000 (Bio-Rad). When we detected phosphorylated $\alpha$-syn, the membrane was incubated in buffer containing $50 \mathrm{~mm} \mathrm{NaF}$ (Machiya et al., 2010). For estimating the expression levels of total $\alpha$-syn or GRK6, we used HEK293 cell lysates overexpressing $\alpha$-syn or GRK6 as standards (Machiya et al., 2010). For estimating the expression levels of Ser129phosphorylated $\alpha$-syn, we prepared recombinant Ser129-phosphorylated 
$\alpha$-syn proteins as standards. The proteins were made by incubation with purified recombinant nonphosphorylated $\alpha$-syn proteins and CK2 as described previously (Machiya et al., 2010). A set of diluted standards was subjected to SDS-PAGE along with samples. After quantifying band intensities of samples with Quantity One software (Bio-Rad), we corrected their relative intensities by plotting them on the standard curve. Statistical comparisons were made by unpaired Student's $t$ test.

\section{Results}

We used rAAV2 to express genes in the rat SNc. To examine the spatial and temporal expression of the genes, we stereotaxically injected rAAV 2 carrying green fluorescent protein (rAAV-GFP) on one side of the adult rat $\mathrm{SNc}$ before experiments of rAAV-A53T $\alpha$-syn injection. Two weeks later, we stained midbrain sections with an anti-tyrosine hydroxylase (TH) antibody to identify dopaminergic neurons (Fig. 1A). GFP was expressed in $\mathrm{TH}-$ positive $\left(\mathrm{TH}^{+}\right)$neurons throughout the SNc. Also, it was expressed in $\mathrm{TH}^{+}$neurons of the SN pars reticulata and the ventral tegmental area, although to a lesser extent. We collected midbrains at 1, 2, 4, and 8 weeks after injection. When compared with the mean band intensity of GFP at 8 weeks by Western blotting, GFP expression increased by $36 \pm 17 \%$ at 1 week after injection and $95 \pm 5 \%$ at 2 weeks after injection (Fig. $1 B, C$ ). This showed that rAAV2-mediated gene expression rapidly reached a steady state by 2 weeks. Based on these findings, we selected 2 and 4 week time points for the analysis of A53T $\alpha$-syn toxicity in nigrostriatal neurons.

Analysis of rAAV2-mediated expression of $\alpha$-syn and GRK6 We coinjected rAAV2 vectors encoding A53T $\alpha$-syn along with either GFP, wild-type (WT) GRK6, or catalytically inactive K215R GRK6 into the rat SNc. In ventral midbrain extracts obtained at 2 weeks after coinjections of rAAV-A53T $\alpha$-syn and rAAV-GFP, Western blotting with a human $\alpha$-syn-specific antibody (LB509) showed unilateral expression of human A53T $\alpha$-syn in the injected side (Fig. 2A). In addition, Western blotting using an $\alpha$-syn antibody (Syn-1), which recognizes both human and rat $\alpha$-syn, showed that the levels of $\alpha$-syn in the injected side were $1.55 \pm 0.32$ times higher than those of endogenous rat $\alpha$-syn in the uninjected side $(n=5)$. Ser129-phosphorylated $\alpha$-syn was undetectable in the injected side by Western blotting using a Ser129phosphorylated $\alpha$-syn-specific monoclonal antibody (psyn\#64). Immunohistochemistry with the LB509 antibody showed that A53T $\alpha$-syn was expressed in virtually all areas of the SNc and striatum in the injected side (Fig. 2A). When midbrain sections were labeled with a Ser129-phosphorylated $\alpha$-syn polyclonal antibody (EYPSYN-01), neurons containing phosphorylated $\alpha$-syn were detected in the injected side of the SNc (Fig. 2A). The amounts of Ser129-phosphorylated $\alpha$-syn were too small in ventral midbrain extracts to be detected by Western blotting.
We also assessed whether coinjection of rAAV-WT GRK6 or rAAV-K215R GRK6 affected the expression of A53T $\alpha$-syn protein. Western blots of ventral midbrain extracts 2 weeks after injection, using the Syn-1 antibody, showed that the expression levels of A53T $\alpha$-syn were similar among the three rAAV coinjections, rAAV-GFP, rAAV-WT GRK6, and rAAV-K215R GRK6 (Fig. 2 B). Histological analysis demonstrated that WT GRK6 was expressed in the injected side of the SNc, and it was coexpressed with A53T $\alpha$-syn in nigral neurons (Fig. 2C). When compared with the expression levels of endogenous GRK6 in the uninjected side, the expression levels of GRK6 in the injected side were $2.07 \pm 0.72$ and $2.45 \pm 0.66$ times greater for rAAV-WT GRK6 $(n=3)$ and rAAV-K215R GRK6 $(n=3)$, respectively (Fig. 2D). There was no significant difference in the expression levels of GRK6 between these groups $(p=0.543)$. We investigated the expression of Ser129-phosphorylated $\alpha$-syn in rats coinjected with rAAV-A53T $\alpha$-syn along with either rAAV-WT GRK6 or rAAV-K215R GRK6. In Western blots of ventral midbrain extracts using the psyn\#64 antibody, coexpression of WT GRK6 clearly yielded Ser129-phosphorylated A53T $\alpha$-syn without changing the levels of total $\alpha$-syn (Fig. 2B). K215R GRK6 failed to generate Ser129-phosphorylated $\alpha$-syn. Consistent with these re- 
A
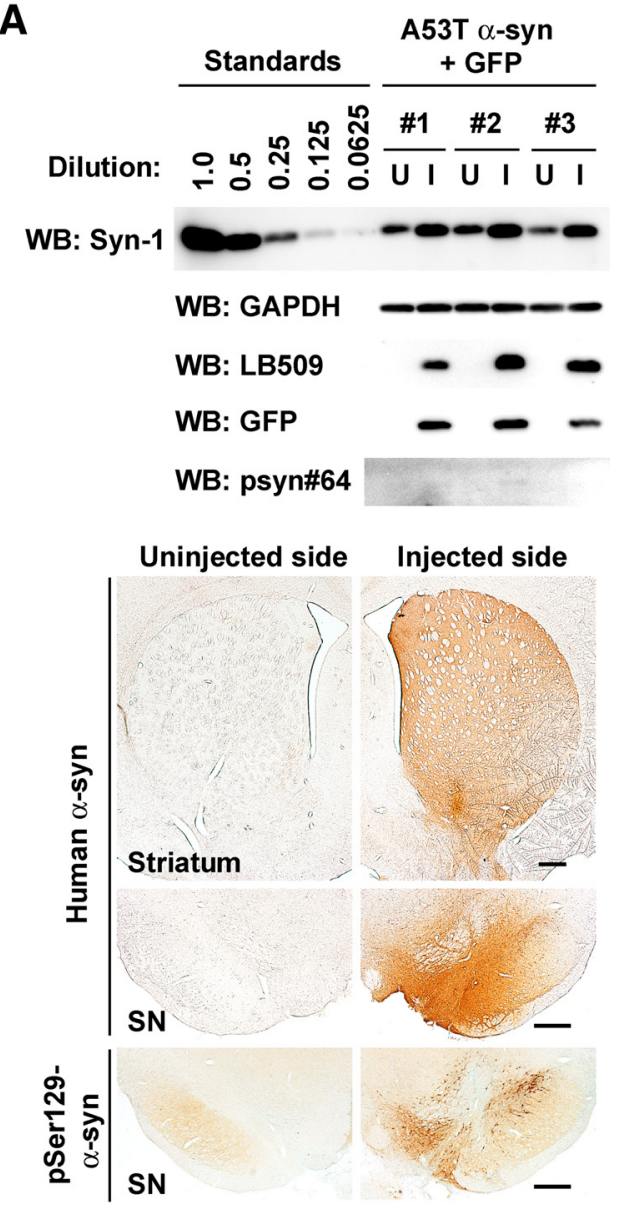

B



C
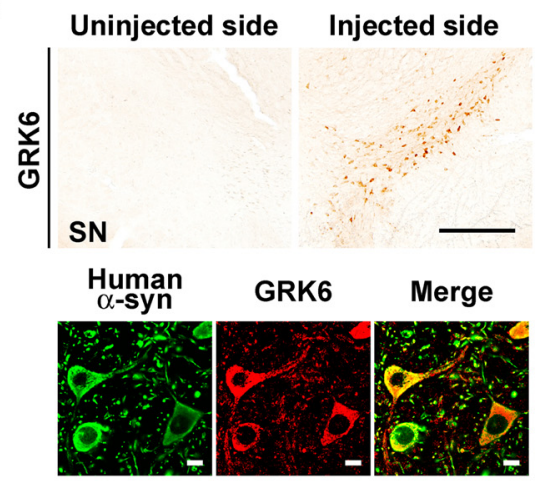

D

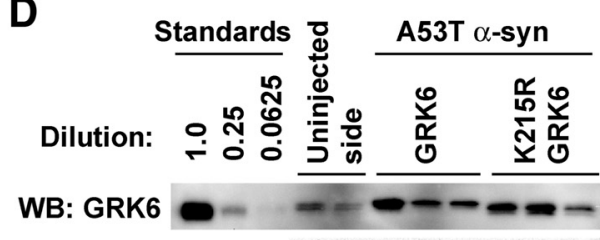

WB: GAPDH

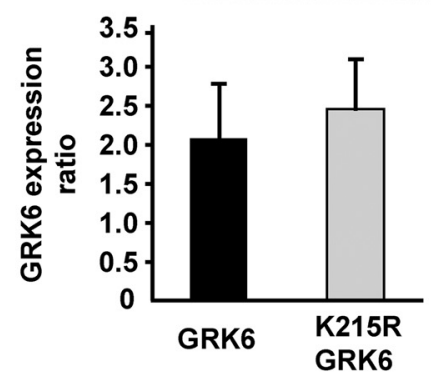

$\mathbf{E}$

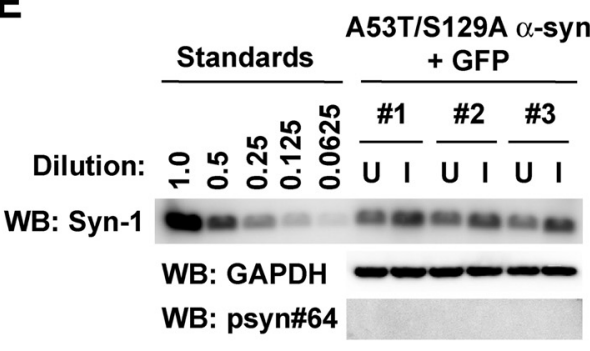

Figure 2. Measurement of $\alpha$-syn and GRK6 expressions in the $\mathrm{SN}$ at 2 weeks after injection. Ventral midbrain tissue extracts from the injected side (I) or uninjected side (U) were subjected to Western blotting. For loading control, the same amounts of samples were also immunoblotted with anti-GAPDH antibody. A, Upper panels show the blots of extracts (10 $\mu \mathrm{g}$ ) from rats (\#1-3) coinjected with rAAV-A53T $\alpha$-syn and rAAV-GFP using Syn-1, LB509, GFP, or psyn\#64 antibody. Lower panels show immunohistochemistry of the striatum and SN sections with LB509 or Ser129-phosphorylated $\alpha$-Syn (EYPSYN-01) antibody. Scale bars, $0.5 \mathrm{~mm}$. B, Extracts (10 $\mu \mathrm{g})$ from rats coinjected with rAAV-A53T $\alpha$-Syn and either rAAV-GFP, rAAV-WT GRK6, or rAAV-K215R GRK6 were analyzed by Western blotting (WB) using psyn\#64, LB509, or Syn-1 antibody. C, Upper panels show immunohistochemistry of the rat SN at 2 weeks after coinjection of rAAV-A53T $\alpha$-syn and rAAV-WT GRK6 with GRK6 antibody. Scale bars, $0.5 \mathrm{~mm}$. Lower panels show double immunofluorescence images of the rat SN. $\alpha$-syn staining (green), GRK6 staining (red), and merged images are shown. Scale bars, $10 \mu \mathrm{m}$. D, Extracts $(20 \mu \mathrm{g})$ from rats coinjected with rAAV-A53T $\alpha$-syn and either rAAV-WT GRK6 or rAAV-K215R GRK6 were analyzed by Western blotting with GRK6 antibody. Graph shows quantitative analysis of GRK6 expression ( $n=3$ in each group). Data represent means \pm SD. $\boldsymbol{E}$, Extracts $(10 \mu \mathrm{g})$ from rats (\#1-3) coinjected with rAAV-A53T/S129A double mutant $\alpha$-syn and rAAV-GFP were analyzed by Western blotting with Syn-1 or psyn\#64 antibody.

sults, immunohistochemistry with the EYPSYN-01 antibody revealed that coexpression of WT GRK6 increased the number of neurons expressing Ser129-phosphorylated $\alpha$-syn in the SNc, while coexpression of K215R GRK6 did not (Fig. 3A,B).

Effect of Ser129-phosphorylated $\alpha$-syn on degeneration of dopaminergic neurons

To assess the loss of dopaminergic neurons, we counted $\mathrm{TH}^{+}$ neurons in the SNc. Surviving $\mathrm{TH}^{+}$neurons in the injected side were represented as percentage to $\mathrm{TH}^{+}$neurons in the uninjected side. Coinjections of rAAV-GFP and rAAV-WT GRK6 led to no significant decrease in the number of $\mathrm{TH}^{+}$neurons, indicating that coexpression of GFP and GRK6 was not toxic during the observation period ( $n=5$ and $n=4$, at 2 weeks and 4 weeks after injection, respectively) (Fig. $3 A-C$ ). In coinjections of rAAVA53T $\alpha$-syn and rAAV-GFP, the expression of A53T $\alpha$-syn caused the progressive loss of dopaminergic neurons in the $\mathrm{SNc}$ as the number of $\mathrm{TH}^{+}$neurons decreased to $63.9 \pm 10.4 \%$ and $37.1 \pm 10.3 \%$, at 2 weeks $(n=6)$ and 4 weeks $(n=3)$ after injection, respectively (Fig. $3 A-C$ ). In coinjections of rAAV- 
A

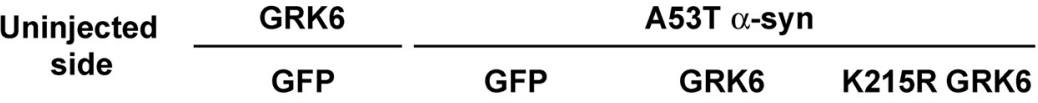

TH

2 wk

\section{Striatum}

SN
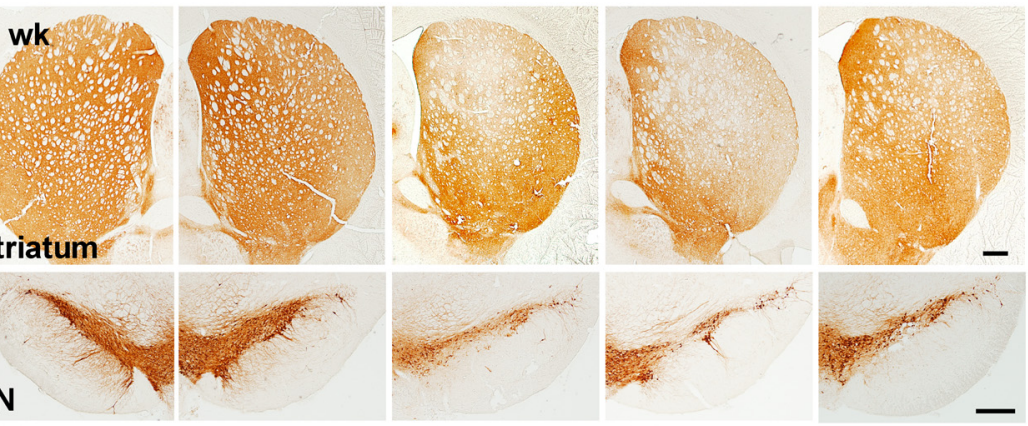

pSer129-

$\alpha$-syn
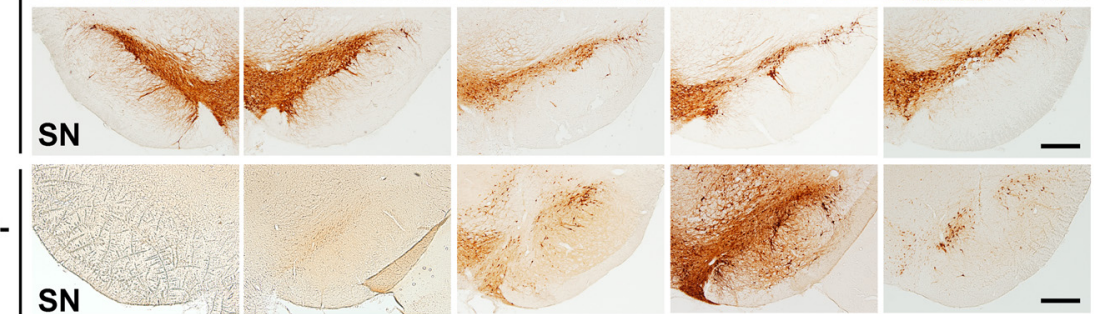

B
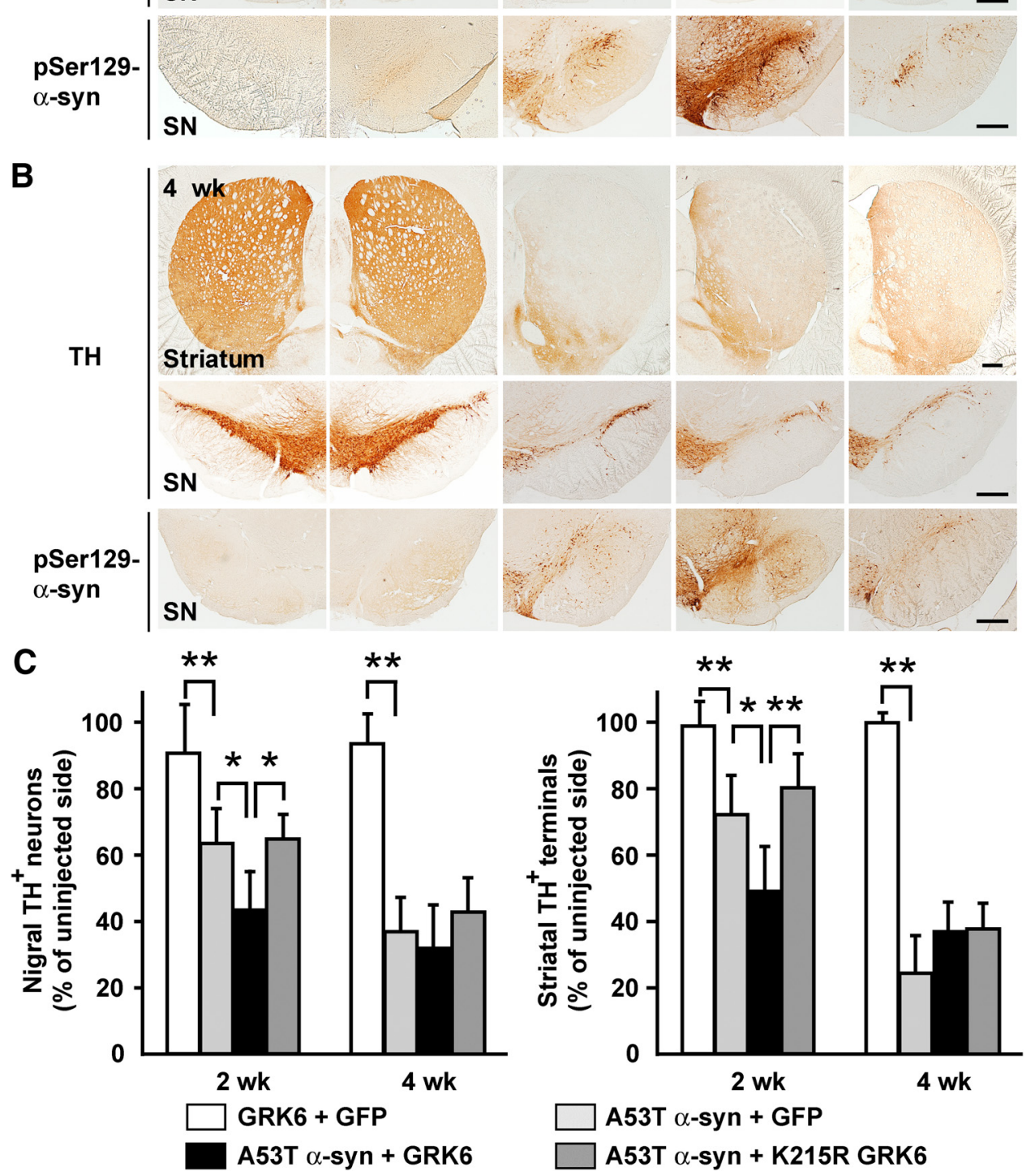

Figure 3. Dopaminergic neuronal loss in rats coinjected with rAAV-A53T $\alpha$-syn and either rAAV-GFP, rAAV-WT GRK6, or rAAV-K215R GRK6. The sections were labeled with antibody to TH or Ser129-phosphorylated $\alpha$-syn. Photomicrographs show representative immunostainings of the injected and uninjected sides of the $\mathrm{SN}$ and striatum at 2 weeks after injection $(\boldsymbol{A})$ and 4 weeks after injection (B). Scale bars, $0.5 \mathrm{~mm}$. C, Graphs show quantitative analysis of nigral $\mathrm{TH}^{+}$neurons and striatal $\mathrm{TH}^{+}$nerve terminals. Data represent means $\pm S D$ and $p$ values were estimated by one-way ANOVA followed by Bonferroni post hoc test $\left({ }^{*} p<0.05,{ }^{* *} p<0.01\right)$.

A53T $\alpha$-syn and rAAV-WT GRK6, the elevated levels of GRK6 significantly accelerated the loss of $\mathrm{TH}^{+}$neurons at 2 weeks after injection $(43.7 \pm 12.0 \%, n=6, p=0.034)$ (Fig. $3 A, C)$. However, the decrease in the number of $\mathrm{TH}^{+}$neurons was similar to that of GFP coexpression at 4 weeks after injection $(31.9 \pm 13.2 \%, n=5$, $p=1.000)($ Fig. $3 B, C)$. Thus, coexpression of GRK6 shortened the time course of A53T $\alpha$-syn-induced degeneration of nigral dopaminergic neurons. We then assessed surviving $\mathrm{TH}^{+}$nerve terminals in the striatum by measuring their optical density. At 2 weeks after injection, coexpression of A53T $\alpha$-syn and GFP de- 


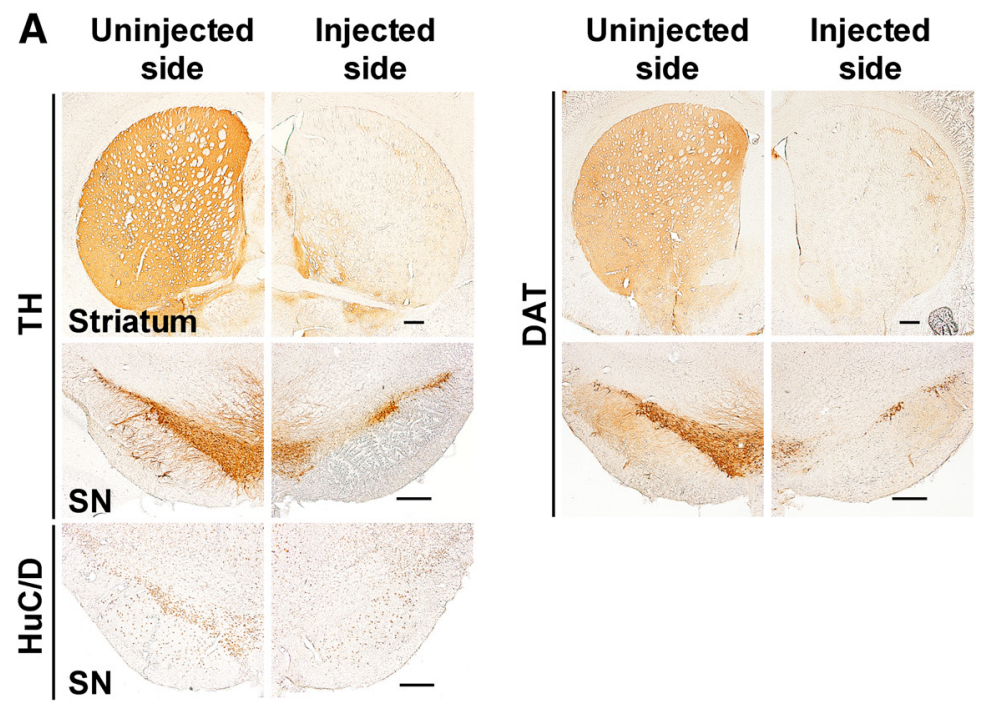

B
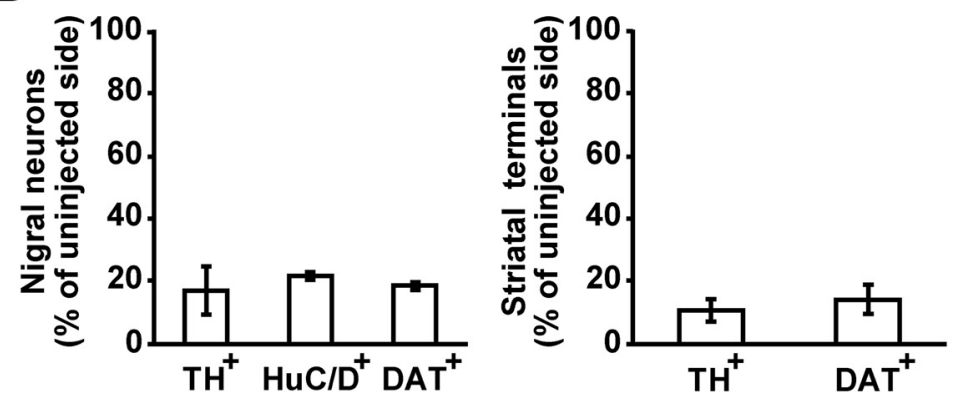

Figure 4. Comparison of the loss of $\mathrm{TH}^{+}$neurons with that of $\mathrm{HuC} / \mathrm{D}^{+}$or DAT ${ }^{+}$neurons in rats coinjected with $\mathrm{rAAV}-\mathrm{A} 53 \mathrm{~T}$ $\alpha$-syn and rAAV-GFP. $\boldsymbol{A}$, The striatal and SN sections at 8 weeks after injection were labeled by antibody to TH, neuron-specific $\mathrm{HuC} / \mathrm{D}$ and dopamine neuron-specific DAT. Scale bars, $0.5 \mathrm{~mm}$. $\boldsymbol{B}$, Left graph shows surviving $\mathrm{TH}^{+}{ }^{+} \mathrm{HuC} \mathrm{D}^{+}$, and DAT ${ }^{+}$neurons in the SNc. Right graph shows surviving $\mathrm{TH}^{+}$and DAT ${ }^{+}$nerve terminals in the striatum.

creased the optical density of $\mathrm{TH}^{+}$nerve terminals to $72.4 \pm$ $11.8 \%(n=6)$, while coexpression of A53T $\alpha$-syn and GRK6 led to a decrease to $49.4 \pm 13.6 \%(n=6)$ (Fig. $3 A, C)$. Consistent with the results in the $\mathrm{SNc}$, coexpression of GRK6 significantly promoted the loss of striatal $\mathrm{TH}^{+}$nerve terminals at 2 weeks after injection $(p=0.013)$ (Fig. $3 A, C)$.

To determine whether GRK6-catalyzed phosphorylation accelerates A53T $\alpha$-syn neurotoxicity, rats were coinjected with rAAV-A53T $\alpha$-syn and rAAV-K215R GRK6. When compared with coexpression of WT GRK6, coexpression of K215R GRK6 was significantly less toxic to the nigral $\mathrm{TH}^{+}$neurons and striatal $\mathrm{TH}^{+}$ nerve terminals at 2 weeks after injection (nigral $\mathrm{TH}^{+}$neurons: $65.2 \pm 7 \%, n=6, p=0.021$; striatal $\mathrm{TH}^{+}$nerve terminals: $80.6 \pm$ $10.5 \%, n=6, p=0.0007$ ) (Fig. $3 A, C$ ). However, no difference in nigral $\mathrm{TH}^{+}$neurons and striatal $\mathrm{TH}^{+}$nerve terminals was seen at 4 weeks after injection (nigral $\mathrm{TH}^{+}$neurons: $43.1 \pm 9.9 \%, n=6, p=$ 0.649 ; striatal $\mathrm{TH}^{+}$nerve terminals: $37.8 \pm 8.0 \%, n=6, p=1.000$ ) (Fig. $3 B, C$ ). The decrease in the number of nigral $\mathrm{TH}^{+}$neurons and the optical density of striatal $\mathrm{TH}^{+}$nerve terminals was similar to that observed with coexpression of A53T $\alpha$-syn and GFP at both 2 and 4 weeks after injection. These data suggested that GRK6-catalyzed Ser129 phosphorylation accelerated A53T $\alpha$-syn neurotoxicity. To assess whether the estimated percentages properly represented the loss of $\mathrm{TH}^{+}$neurons in the SNc, we compared the sum of nigral $\mathrm{TH}^{+}$neurons that were counted in the uninjected sides used as internal control. No significant difference was found in the total number of nigral $\mathrm{TH}^{+}$neurons in the uninjected sides among dif- ferent groups $(1363.60 \pm 101.99$ cells, $1293.17 \pm 342.17$ cells, $1348.0 \pm 309.78$ cells, and $1286.0 \pm 281.05$ cells in coexpressions of GFP + GRK6, A53T $\alpha$-syn + GFP, A53T $\alpha$-syn + WT GRK6, and A53T $\alpha$-syn + K215R GRK6, respectively, $p>0.05$ ).

To confirm whether the disappearance of TH immunoreactivity in nigral neurons really reflected the loss of nigral neurons, we performed immunohistochemistry using an antibody against a pan-neuronal marker, $\mathrm{HuC} / \mathrm{D}$, and an antibody against another specific marker of dopaminergic neurons, dopamine transporter (DAT) (Fig. 4A). In coinjections of rAAV-A53T $\alpha$-syn and rAAV-GFP, there was no significant difference among the number of $\mathrm{TH}^{+}$neurons $(17 \pm 7.8 \%, n=$ 3), $\mathrm{HuC} / \mathrm{D}^{+}$neurons $(21.9 \pm 1.2 \%, n=$ $3)$, and DAT ${ }^{+}$neurons (18.59 $\pm 1.12 \%$, $n=3$ ) at 8 weeks after injection (Fig. $4 B$ ). Additionally, a decrease in striatal $\mathrm{DAT}^{+}$ nerve terminals $(14.35 \pm 4.99 \%, n=3)$ was similar to that in $\mathrm{TH}^{+}$ones $(10.79 \pm$ 3.74\%, $n=3$ ) (Fig. 4B).

\section{Effect of Ser129 phosphorylation on A53T $\alpha$-syn-induced morphological changes in dopaminergic neurons}

To investigate the morphological changes induced by Ser129-phosphorylated $\alpha$-syn, we immunostained brain sections from rats coinjected with rAAV-A53T $\alpha$-syn and rAAV-GFP using the human $\alpha$-syn-specific LB509 antibody. In the SN, A53T $\alpha$-syn formed coarse granular deposits in the neuronal perikarya and accumulated in swollen neurites at 2 weeks after injection (Fig. 5A). In the striatum, $\alpha$-syn was found to be present in swollen neurites and normalappearing axons (Fig. $5 A, B$ ). Swollen neurites were also labeled with the antibody to $\mathrm{TH}$ (Fig. $5 A$ ). No large aggregates resembling LBs were found. At 4 weeks after injection, $\alpha$-syn-positive swollen neurites in the striatum were detected more easily because of a decrease in normal axon terminals (Fig. 5B). At 2 and 4 weeks after injection, a smaller number of swollen neurites in the striatum were immunoreactive for Ser129-phosphorylated $\alpha$-syn (Fig. 5A, B). In the $\alpha$-syn-positive structures, striatal swollen neurites were formed abundantly in accordance with the extensive neuritic pathology in brains of familial PD with the A53T $\alpha$-syn gene mutation (Spira et al., 2001; Duda et al., 2002). We then analyzed the sections from rats coinjected with rAAV-A53T $\alpha$-syn and rAAV-WT GRK6. In the striatum, swollen neurites containing Ser129-phosphorylated $\alpha$-syn were more numerous at 2 weeks after injection (Fig. 5B). Ser129-phosphorylated $\alpha$-syn-immunoreactivity in normal axons was much weaker than that in swollen neurites (Fig. 5B). The number of swollen neurites containing Ser129-phosphorylated $\alpha$-syn increased during the observation period (Fig. 5B). However, immunohistochemistry using the LB509 antibody showed that the number of surviving swollen neurites containing total $\alpha$-syn in WT GRK6 coexpression was almost the same as that observed in GFP coexpression (Fig. 5B). $\alpha$-syn-positive swollen neurites were also found in K215R GRK6 coexpression (Fig. 5B). There was no significant 
A

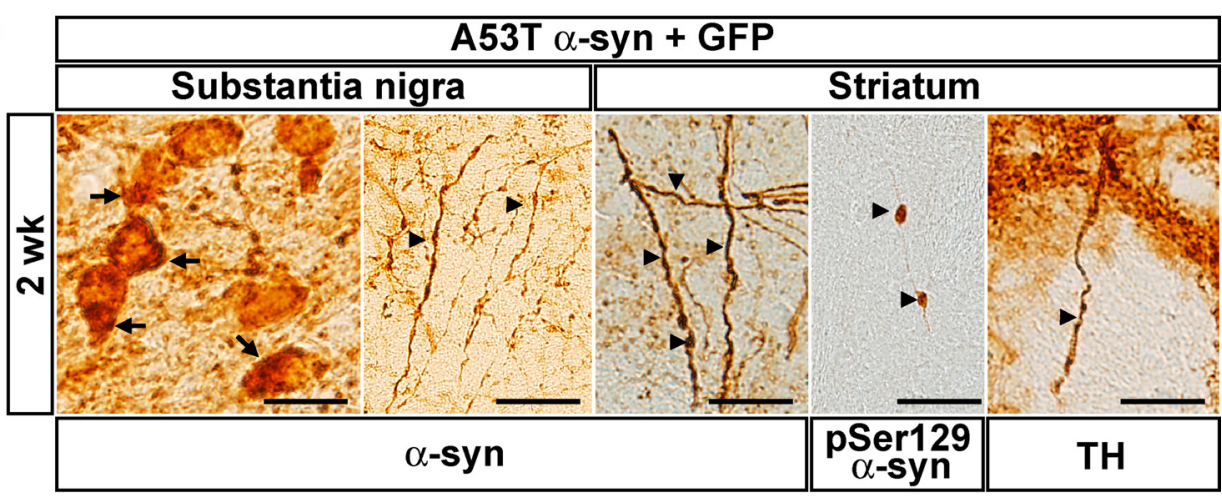

B
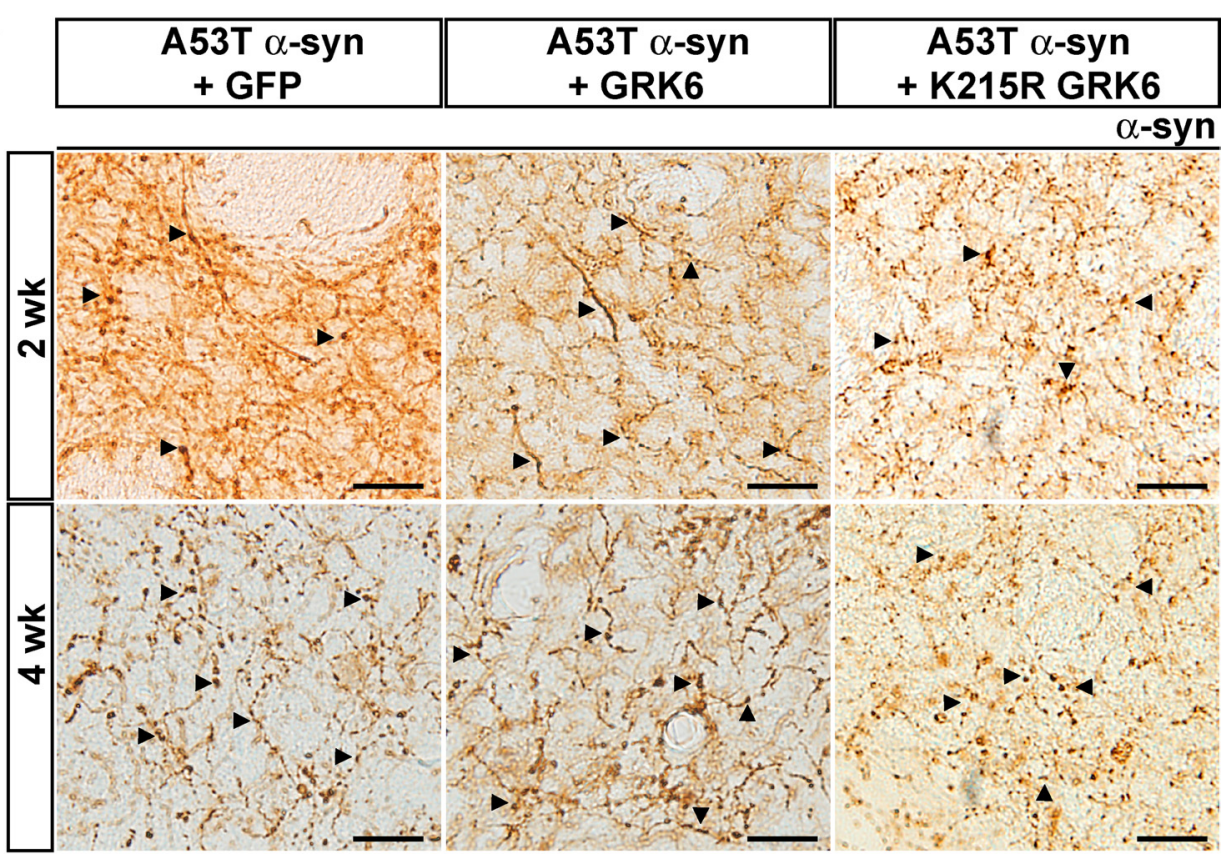

pSer129 $\alpha$-syn

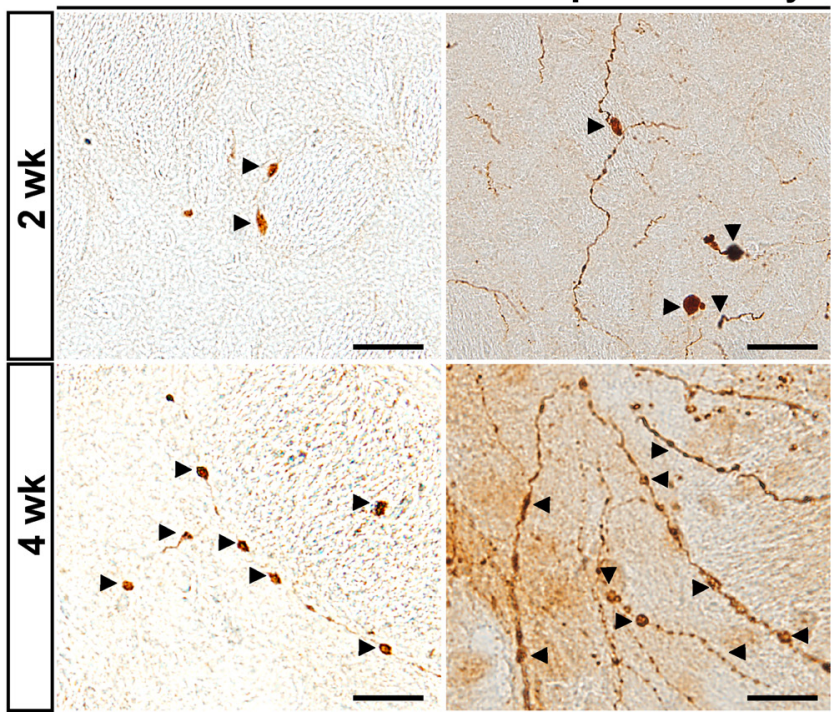

Figure 5. Morphological changes of dopaminergic neurons in rats coinjected with rAAV-A53T $\alpha$-syn and either rAAV-GFP, rAAV-WT GRK6, or rAAV-K215R GRK6. $A$, Nigrostriatal neurons in rats at 2 weeks after coinjection of rAAV-A53T $\alpha$-syn and rAAV-GFP. The SN and striatum sections were immunostained with LB509 ( $\alpha$-syn), EYPSYN-01 (pSer129 $\alpha$-syn), or TH antibody. $\boldsymbol{B}$, Comparison of the formation of $\alpha$-syn-positive swollen neurites in the striatum. Upper panels, The striatum sections from rats coinjected with rAAV-A53T $\alpha$-syn and either rAAV-GFP, rAAV-WT GRK6, or rAAV-K215R GRK6 were immunostained with LB509 antibody. Lower panels, The striatum sections from rats coinjected with rAAV-A53T $\alpha$-syn and either rAAV-GFP or rAAV-WT GRK6 were als0 immunostained with EYPSYN-01 antibody. Photomicrographs show the data at 2 weeks and 4 weeks after injection. Arrows and arrowheads indicate granular deposits and swollen neurites, respectively. Scale bars, $20 \mu \mathrm{m}$. 
A

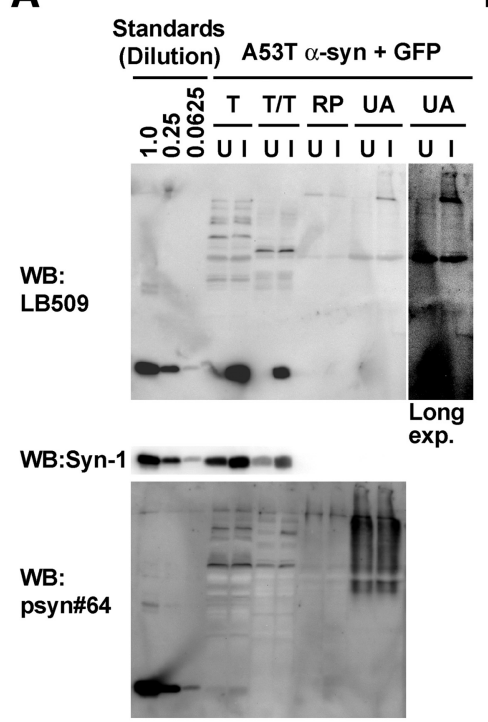

B Standards (Dilution) A53T $\alpha$-syn + GRK6

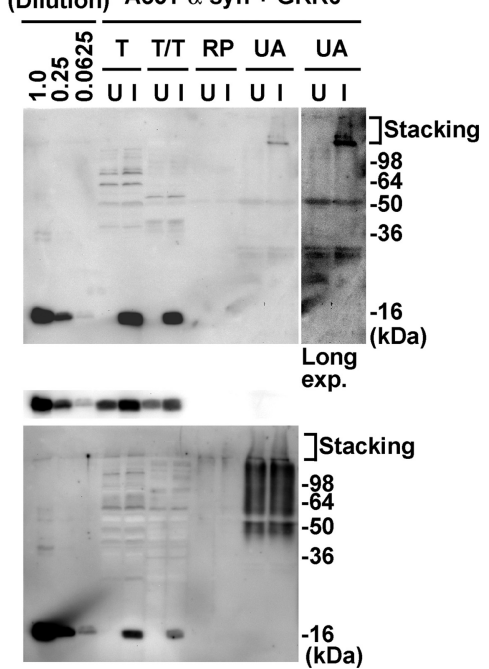

Figure 6. Effect of Ser129 phosphorylation on solubility changes of A53T $\alpha$-syn. Ventral midbrain tissues from the injected side (I) or uninjected side (U) at 2 weeks after injection were sequentially extracted. Equal amounts (20 $\mu \mathrm{g})$ of TBS-soluble fractions (T), TBS-insoluble/Triton X-100-soluble fractions (T/T), Triton X-100-insoluble/RIPA-soluble fractions (RP), and RIPA-insoluble/ureasoluble fractions (UA) were subjected to Western blotting (WB) with LB509, Syn-1, or psyn\#64 antibody. As standard proteins, the same set of diluted recombinant $\alpha$-syn or phosphorylated $\alpha$-syn proteins were loaded simultaneously. Panels show the blots of coinjections of rAAV-A53T $\alpha$-syn and rAAV-GFP ( $\boldsymbol{A})$, and rAAV-A53T $\alpha$-syn and rAAV-WT GRK6 ( $\boldsymbol{B}$ ). The right panels (Long exp.) of $\boldsymbol{A}$ and $\boldsymbol{B}$ show the same blots of urea fractions after long exposure.

difference in their number between WT GRK6 and K215R GRK6 coexpressions (Fig. 5B). These data demonstrated that Ser129phosphorylated $\alpha$-syn was preferentially distributed to swollen neurites. However, the increased levels of Ser129-phosphorylated $\alpha$-syn did not promote the formation of swollen neurites in dopaminergic neurons.

\section{Effect of Ser129 phosphorylation on solubility changes of A53T $\alpha$-syn}

Accumulation of radioimmunoprecipitation assay (RIPA)insoluble, urea-soluble $\alpha$-syn has been reported to be a characteristic feature of PD and DLB (Tofaris et al., 2003), as well as in transgenic mice overexpressing C-terminal truncated $\alpha$-syn (Michell et al., 2007). To examine the solubility of $\alpha$-syn, we sequentially extracted the protein from ventral midbrains 2 weeks after injection, using Tris-buffered saline (TBS), 1\% Triton X-100, RIPA buffer, and $8 \mathrm{M}$ urea/5\% SDS (Tofaris et al., 2003). In coinjections of rAAV-A53T $\alpha$-syn and rAAV-GFP, Western blotting with the LB509 antibody detected the gel-excluded material in the RIPA-insoluble/urea-soluble fraction from the injected side (Fig. 6A). After long exposure, the gel-excluded material was observed as a band at the interface of the resolving/stacking gel with a faint smear in the stacking gel. These corresponded to detergent-insoluble aggregates of A53T $\alpha$-syn. Additionally, a band of $17 \mathrm{kDa}$ was detected by the LB509 antibody in the TBSsoluble fraction and in the TBS-insoluble/Triton X-100-soluble fraction from the injected side. It corresponded to monomeric A53T $\alpha$-syn with normal solubility, because the fractionation pattern was similar to that of rat endogenous $\alpha$-syn monomers in the blots of the uninjected side with the Syn-1 antibody (Fig. 6A). Western blotting with the Ser129-phosphorylated $\alpha$-syn-specific psyn\#64 antibody showed the gel-excluded material and the high-molecular-weight smear in the RIPA-insoluble/ureasoluble fraction from the injected side (Fig. 6A). However, these immunoreactivities were also found in the fraction from the uninjected side, indicating that they were nonspecific. In coinjections of rAAV-A53T $\alpha$-syn and rAAV-WT GRK6, Western blotting with the LB509 antibody showed that the amounts of the gel-excluded material in GRK6 coexpression were nearly identical to those observed in GFP coexpression when compared with the reference signals of recombinant $\alpha$-syn proteins (Fig. $6 A, B)$. Also, we did not find bands corresponding to soluble oligomers of $\alpha$-syn. Coexpression of GRK6 simply increased levels of monomeric Ser129-phosphorylated $\alpha$-syn with normal solubility.

\section{Effect of the phosphorylation- incompetent S129A mutation on A53T $\alpha$-syn-induced degeneration}

To further investigate the role of Ser 129 phosphorylation in A53T $\alpha$-syn neurotoxicity, we coinjected rAAV-phosphorylation-incompetent A53T/S129A double mutant $\alpha$-syn along with either rAAV-GFP or rAAV-WT GRK6. In ventral midbrain extracts at 2 weeks after coinjection of rAAV-A53T/S129A $\alpha$-syn and rAAV-GFP, Western blotting with the Syn- 1 antibody showed that the expression levels of $\alpha$-syn in the injected side were $1.41 \pm 0.12$ times higher than those of endogenous $\alpha$-syn in the uninjected side $(n=4)$ (Fig. $2 E)$. The expression of $\alpha$-syn was comparable with that in coinjections of rAAV-A53T $\alpha$-syn and rAAV-GFP ( $p=0.425)$. In coinjections of rAAV-A53T/S129A $\alpha$-syn and rAAV-GFP, the number of nigral $\mathrm{TH}^{+}$neurons decreased with the optical density of striatal $\mathrm{TH}^{+}$nerve terminals during the observation period $(n=4$ and 3 at 2 and 4 weeks after injection, respectively) (Fig. $7 A-C$ ). When compared with coexpression of A53T $\alpha$-syn and GFP, no significant difference in the number of nigral $\mathrm{TH}^{+}$neurons and the optical density of striatal $\mathrm{TH}^{+}$nerve terminals was observed in coexpression of A53T/S129A $\alpha$-syn and GFP (Fig. 7A-C). In coinjections of rAAV-A53T/S129A $\alpha$-syn and rAAV-WT GRK6, the loss of $\mathrm{TH}^{+}$neurons and $\mathrm{TH}^{+}$nerve terminals was comparable with that observed with coexpression of A53T/S129A $\alpha$-syn and GFP (Fig. 7A-C). When compared with coexpression of A53T $\alpha$-syn and GRK6, expression of A53T/S129A $\alpha$-syn significantly suppressed the loss of $\mathrm{TH}^{+}$neurons $(70.5 \pm 19.2 \%, n=6$, $p=0.030)$ and striatal $\mathrm{TH}^{+}$nerve terminals $(91.7 \pm 9.0 \%, n=6$, $p=0.00003$ ) at 2 weeks after injection (Fig. $7 A, C$ ). However, there was no significant difference in the number of nigral $\mathrm{TH}^{+}$ neurons $(54.2 \pm 16.3 \%, n=5, p=0.136)$ and the optical density of the striatal $\mathrm{TH}^{+}$nerve terminals $(60.9 \pm 22.5 \%, n=5, p=$ 0.244 ) at 4 weeks after injection (Fig. $7 B, C$ ). Also, no significant difference was found in the sum of nigral $\mathrm{TH}^{+}$neurons that were counted in the uninjected sides among different groups $(1293.17 \pm 342.17$ cells, $1348.0 \pm 309.78$ cells, $1631.25 \pm$ 255.98 cells, and $1544 \pm 309.91$ cells in coexpressions of A53T $\alpha$-syn + GFP, A53T $\alpha$-syn + WT GRK6, A53T/S129A $\alpha$-syn + GFP, and A53T/S129A $\alpha$-syn + WT GRK6, respectively, $p>$ $0.05)$. These findings demonstrated that the phosphorylationincompetent S129A mutation did not alter A53T $\alpha$-syn neurotoxicity, and that GRK6-catalyzed Ser129 phosphorylation enhanced 
A53T $\alpha$-syn toxicity. We then immunostained brain sections from rats coinjected with rAAV-A53T/S129A $\alpha$-syn and rAAVGFP using the LB509 antibody (Fig. 7D). In the SN, A53T/S129A $\alpha$-syn formed coarse granular deposits in the neuronal perikarya at 2 weeks after injection. In the striatum, it accumulated in swollen neurites at 2 and 4 weeks after injection. Swollen neurites were also labeled with the antibody to TH. When analyzing the striatal sections from rats coinjected with rAAV-A53T/S129A $\alpha$-syn and rAAV-WT GRK6, the formation of $\alpha$-syn-positive swollen neurites in WT GRK6 coexpression was almost similar to that in GFP coexpression (Fig. 7D). Also, no obvious difference in the appearance of $\alpha$-syn-positive structures was found between A53T/S129A $\alpha$-syn and A53T $\alpha$-syn coexpressions (Figs. 5B, 7D).

\section{Discussion}

In this study, we showed that increased levels of Ser129-phosphorylated $\alpha$-syn moderately but significantly enhances A53T $\alpha$-syn toxicity in the rAAV-based rat model. This finding is consistent with experiments using the transgenic fly model coexpressing WT $\alpha$-syn and a Drosophila homolog of GRK2 (Chen and Feany, 2005). However, the rAAV-based rat models expressing the phosphorylation-mimic S129D $\alpha$-syn yielded conflicting results (Gorbatyuk et al., 2008; Azeredo da Silveira et al., 2009; McFarland et al., 2009). In these rat models, S129D $\alpha$-syn did not accelerate $\alpha$-syn toxicity. The lack of concordance questions the use of S129D $\alpha$-syn to examine the effect of Ser 129 phosphorylation on $\alpha$-syn toxicity in in vivo models of $\mathrm{PD}$, although phosphorylation-mimic mutation (a serine to aspartate or glutamate substitution) are often used to study the structural and functional influences of phosphorylated proteins. Previous in vitro experiments demonstrated that Ser129 phosphorylation disrupted the intramolecular long-range interaction of WT $\alpha$-syn; however, S129D $\alpha$-syn did not show the same effect (Paleologou et al., 2008). In addition, S129D $\alpha$-syn failed to recapitulate the effect of Ser129 phosphorylation on $\alpha$-syn fibrillation. Furthermore, the half-life of S129D $\alpha$-syn was much longer than that of authentically Ser129-phosphorylated $\alpha$-syn in the cultured cells (Machiya et al., 2010). Thus, S129D $\alpha$-syn did not reproduce the biophysical and biochemical properties, such as structure, aggregation, and protein stability, of authentically Ser129-phosphorylated $\alpha$-syn in vitro. Our results suggest that the toxic effects of Ser129-phosphorylated $\alpha$-syn are commonly observed in both
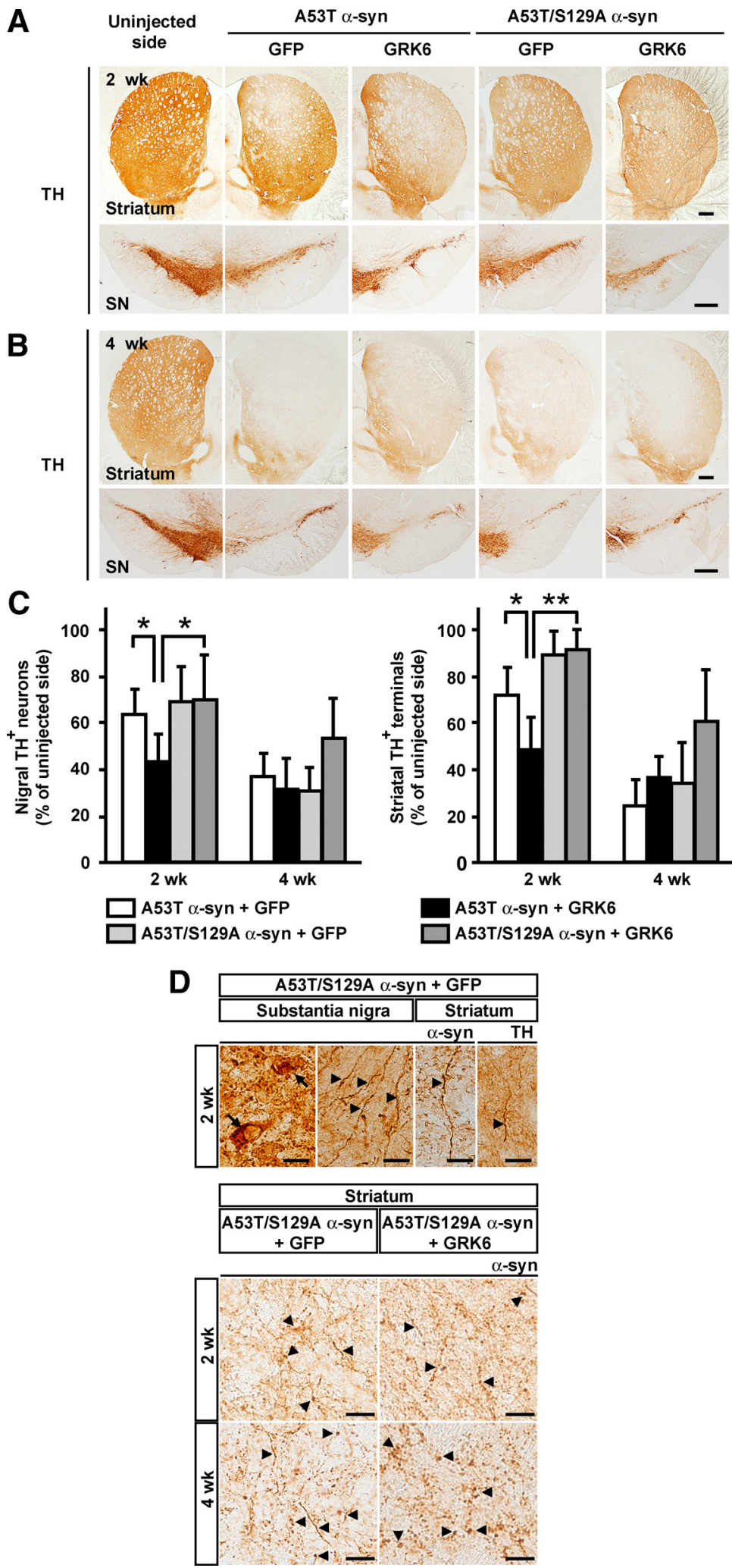

Figure 7. Dopaminergic neuronal loss in rats coinjected with rAAV-phosphorylation-incompetent A53T/S129A double mutant $\alpha$-syn and either rAAV-GFP or rAAV-WT GRK6. Tissue sections were labeled with antibody to TH. Photomicrographs show representative immunostainings of the injected and uninjected sides of the striatum and SN at 2 weeks after injection $(\boldsymbol{A})$ and 4 weeks after injection $(\boldsymbol{B})$. Scale bars, $0.5 \mathrm{~mm}$. C, Graphs show quantitative analysis of nigral $\mathrm{TH}^{+}$neurons and striatal $\mathrm{TH}^{+}$nerve terminals. Data represent means \pm SD and $p$ values $\left({ }^{*} p<0.05,{ }^{* *} p<0.01\right)$.D , Morphological changes of dopaminergic neurons in rats coinjected with rAAV-A53T/S129A $\alpha$-Syn and either rAAV-GFP or rAAV-WT GRK6. Upper panels, TheSN and striatum sections from rats coinjected with rAAV-A53T/S129A $\alpha$-syn and rAAV-GFP were immunostained with LB509 ( $\alpha$-syn) or TH antibody. Lower panels, The striatum sections from rats coinjected with rAAVA53T/S129A $\alpha$-syn and either rAAV-GFP or rAAV-WT GRK6 were immunostained with LB509 ( $\alpha$-syn) antibody. Arrows and arrowheads indicate granular deposits and swollen neurites, respectively. Scale bars: $A, B, 0.5 \mathrm{~mm} ; \boldsymbol{D}, 20 \mu \mathrm{m}$. 
fly and rat models expressing authentically phosphorylated form, but not the phosphorylation-mimic mutant. This is consistent with recent findings that enhanced protein phosphatase $2 \mathrm{~A}$ (PP2A) activity reduced the levels of Ser129-phosphorylated $\alpha$-syn and improved motor performance in WT $\alpha$-syn transgenic mice (Lee et al., 2011). In this study, we expressed A53T mutant $\alpha$-syn in the SNc. A53T mutant $\alpha$-syn is reported to accelerate fibril formation compared with wild-type $\alpha$-syn in vitro (Conway et al., 1998). In the transgenic mice, A53T mutant $\alpha$-syn is also revealed to cause greater neurotoxicity than wild-type $\alpha$-syn (Lee et al., 2002; Maingay et al., 2005; Dawson et al., 2010). In our model, coexpression of A53 T mutant $\alpha$-syn and GFP developed overt degeneration of dopaminergic neurons. More than $50 \%$ of neurons were progressively lost by 4 weeks. Taking advantage of A53T mutant $\alpha$-syn, we could find temporal changes in the effect of Ser129-phosphorylation on $\alpha$-syninduced degeneration of dopaminergic neurons. Further in vivo studies using mammalian models that express various levels of authentically phosphorylated $\alpha$-syn would be valuable to more fully appreciate the accurate effect of Ser 129 phosphorylation of $\alpha$-syn. In addition, the model expressing WT $\alpha$-syn would provide crucial insight for understanding the role of Ser 129 phosphorylation in the pathogenesis of sporadic PD.

Accumulating evidence indicates that prefibrillar intermediates of $\alpha$-syn, such as soluble oligomers and protofibrils, are highly toxic and contribute to neurodegeneration, while mature fibrils are less toxic (Volles et al., 2001; Xu et al., 2002; Eriksen et al., 2003; Lee and Trojanowski, 2006). To investigate the mechanisms by which Ser 129 phosphorylation accelerates A53T $\alpha$-syn toxicity, we examined its effect on the morphology of dopaminergic neurons and on the solubility of A53T $\alpha$-syn. Our data demonstrated that Ser 129-phosphorylated $\alpha$-syn did not significantly contribute to the swelling of neurites. Furthermore, coexpression of GRK6 did not generate soluble oligomers and detergent-insoluble aggregates of $\alpha$-syn. Coexpression of GRK6 merely increased the amounts of Ser129-phosphorylated $\alpha$-syn monomers with normal solubility. Do these results indicate that there is no relationship between the toxic effects of Ser129phosphorylated $\alpha$-syn and the formation of soluble oligomers or detergent-insoluble aggregates of $\alpha$-syn? In this study, we found no obvious contribution of detergent-insoluble aggregates of $\alpha$-syn to the toxic effect of Ser129-phosphorylated $\alpha$-syn, whereas we could not exclude the role of soluble oligomers in exerting the toxic effect of Ser129-phosphorylated $\alpha$-syn. We may fail to detect soluble oligomers of $\alpha$-syn by performing conventional SDS-PAGE. Chen et al. (2009) reported that Ser129 phosphorylation increased the levels of soluble oligomers of $\alpha$-syn in the fly model of PD. In this paper, they detected soluble oligomers of Ser129-phosphorylated $\alpha$-syn by loading brain extracts onto the acrylamide gel without heating. It is possible that the difference in experimental procedures caused the discrepancy. Also, the amounts of soluble oligomers of $\alpha$-syn may simply be too low to detect in our model. Earlier research demonstrated that, for amyloidogenesis, rapid polymerization can occur by monomer addition in the absence of oligomeric intermediates (Collins et al., 2004). The increased levels of Ser129-phosphorylated $\alpha$-syn may promote the formation of detergent-insoluble aggregates via a similar pathway in our model, although without altering the amounts of detergent-insoluble aggregates of $\alpha$-syn. Alternative possibility is that soluble monomers of Ser129-phosphorylated $\alpha$-syn may be toxic. In the A53T $\alpha$-syn and GRK6 coexpression experiments, Ser129-phosphorylated $\alpha$-syn initially promoted $\alpha$-syn toxicity without affecting swollen neurite formation. This is in accordance with the results of the transgenic fly model showing that coexpression of WT $\alpha$-syn and GRK2 enhanced $\alpha$-syn toxicity with- out altering inclusion formation (Chen and Feany, 2005). These findings may be explainable by an idea that the rapid elevation of Ser129-phosphorylated $\alpha$-syn monomers causes transient damage to dopaminergic neurons in an aggregation-independent manner. Although the normal function of Ser129-phosphorylated $\alpha$-syn remains unclear, Ser129 phosphorylation is reported to reduce the ability of $\alpha$-syn to regulate the tyrosine hydroxylase activity (Lou et al., 2010). The transient damage of Ser129-phosphorylated $\alpha$-syn may be associated with its function in dopamine metabolism.

The extent of degeneration mediated by A53T/S129A $\alpha$-syn double mutant, which cannot be phosphorylated, was similar to that produced by A53T $\alpha$-syn single mutant. Although in coexpression of A53T $\alpha$-syn and GFP small amounts of A53T $\alpha$-syn underwent endogenous kinase-mediated Ser129 phosphorylation in dopaminergic neurons, the levels of Ser129-phosphorylated $\alpha$-syn seem to be insufficient to enhance A53T $\alpha$-syn toxicity. This may be due to a mechanism that keeps Ser129-phosphorylated $\alpha$-syn at a low level for protecting neurons from additional toxicity of $\alpha$-syn. The levels of Ser129-phosphorylated $\alpha$-syn are regulated with the interplay among $\alpha$-syn, kinases (Inglis et al., 2009; Sakamoto et al., 2009), phosphatase (Lee et al., 2011), and the degradation pathway of Ser129-phosphorylated $\alpha$-syn (Machiya et al., 2010). Conversely, impairment of the regulatory mechanism may increase the proportion of Ser129-phosphorylated form in total $\alpha$-syn, causing its toxic effect. Also, we found that coexpression of K215R catalytically inactive GRK6 abolished the ability of Ser129 phosphorylation to exacerbate $\alpha$-syn toxicity. This suggests that the effects of Ser 129 phosphorylation on $\alpha$-syn toxicity can be reduced by inhibiting kinase activity, if the proportion of Ser129-phosphorylated $\alpha$-syn is increased in the disease state. The identification of the kinases that contribute to Ser 129 phosphorylation of $\alpha$-syn in vivo should aid the development of therapeutic strategies that target $\alpha$-syn-kinase interactions in PD.

\section{References}

Anderson JP, Walker DE, Goldstein JM, de Laat R, Banducci K, Caccavello RJ, Barbour R, Huang J, Kling K, Lee M, Diep L, Keim PS, Shen X, Chataway T, Schlossmacher MG, Seubert P, Schenk D, Sinha S, Gai WP, Chilcote TJ (2006) Phosphorylation of Ser-129 is the dominant pathological modification of alpha-synuclein in familial and sporadic Lewy body disease. J Biol Chem 281:29739-29752.

Arawaka S, Wada M, Goto S, Karube H, Sakamoto M, Ren CH, Koyama S, Nagasawa H, Kimura H, Kawanami T, Kurita K, Tajima K, Daimon M, Baba M, Kido T, Saino S, Goto K, Asao H, Kitanaka C, Takashita E, et al. (2006) The role of G-protein-coupled receptor kinase 5 in pathogenesis of sporadic Parkinson's disease. J Neurosci 26:9227-9238.

Azeredo da Silveira S, Schneider BL, Cifuentes-Diaz C, Sage D, Abbas-Terki T, Iwatsubo T, Unser M, Aebischer P (2009) Phosphorylation does not prompt, nor prevent, the formation of alpha-synuclein toxic species in a rat model of Parkinson's disease. Hum Mol Genet 18:872-887.

Chen L, Feany MB (2005) Alpha-synuclein phosphorylation controls neurotoxicity and inclusion formation in a Drosophila model of Parkinson disease. Nat Neurosci 8:657-663.

Chen L, Periquet M, Wang X, Negro A, McLean PJ, Hyman BT, Feany MB (2009) Tyrosine and serine phosphorylation of alpha-synuclein have opposing effects on neurotoxicity and soluble oligomer formation. J Clin Invest 119:3257-3265.

Ciron C, Cressant A, Roux F, Raoul S, Cherel Y, Hantraye P, Déglon N, Schwartz B, Barkats M, Heard JM, Tardieu M, Moullier P, Colle MA (2009) Human alpha-iduronidase gene transfer mediated by adenoassociated virus types 1,2 , and 5 in the brain of nonhuman primates: vector diffusion and biodistribution. Hum Gene Ther 20:350-360.

Collins SR, Douglass A, Vale RD, Weissman JS (2004) Mechanism of prion propagation: amyloid growth occurs by monomer addition. PLoS Biol 2:e321.

Conway KA, Harper JD, Lansbury PT (1998) Accelerated in vitro fibril for- 
mation by a mutant alpha-synuclein linked to early-onset Parkinson disease. Nat Med 4:1318-1320.

Cookson MR (2009) alpha-Synuclein and neuronal cell death. Mol Neurodegener 4:9.

Dawson TM, Ko HS, Dawson VL (2010) Genetic animal models of Parkinson's disease. Neuron 66:646-661.

Donello JE, Beeche AA, Smith GJ 3rd, Lucero GR, Hope TJ (1996) The hepatitis B virus posttranscriptional regulatory element is composed of two subelements. J Virol 70:4345-4351.

Duda JE, Giasson BI, Mabon ME, Miller DC, Golbe LI, Lee VM, Trojanowski JQ (2002) Concurrence of alpha-synuclein and tau brain pathology in the Contursi kindred. Acta Neuropathol 104:7-11.

Erdtmann-Vourliotis M, Mayer P, Ammon S, Riechert U, Höllt V (2001) Distribution of G-protein-coupled receptor kinase (GRK) isoforms 2, 3, 5 and 6 mRNA in the rat brain. Brain Res Mol Brain Res 95:129-137.

Eriksen JL, Dawson TM, Dickson DW, Petrucelli L (2003) Caught in the act: alpha-synuclein is the culprit in Parkinson's disease. Neuron 40:453-456.

Fehr C, Fickova M, Hiemke C, Reuss S, Dahmen N (1997) Molecular cloning of rat G-protein-coupled receptor kinase 6 (GRK6) from brain tissue, and its mRNA expression in different brain regions and peripheral tissues. Brain Res Mol Brain Res 49:278-282.

Fitzsimons HL, Bland RJ, During MJ (2002) Promoters and regulatory elements that improve adeno-associated virus transgene expression in the brain. Methods 28:227-236.

Fujiwara H, Hasegawa M, Dohmae N, Kawashima A, Masliah E, Goldberg MS, Shen J, Takio K, Iwatsubo T (2002) alpha-Synuclein is phosphorylated in synucleinopathy lesions. Nat Cell Biol 4:160-164.

Gorbatyuk OS, Li S, Sullivan LF, Chen W, Kondrikova G, Manfredsson FP, Mandel RJ, Muzyczka N (2008) The phosphorylation state of Ser-129 in human alpha-synuclein determines neurodegeneration in a rat model of Parkinson disease. Proc Natl Acad Sci U S A 105:763-768.

Inglis KJ, Chereau D, Brigham EF, Chiou SS, Schöbel S, Frigon NL, Yu M, Caccavello RJ, Nelson S, Motter R, Wright S, Chian D, Santiago P, Soriano F, Ramos C, Powell K, Goldstein JM, Babcock M, Yednock T, Bard F, et al. (2009) Polo-like kinase 2 (PLK2) phosphorylates alpha-synuclein at serine 129 in central nervous system. J Biol Chem 284:2598-2602.

Kirik D, Rosenblad C, Burger C, Lundberg C, Johansen TE, Muzyczka N, Mandel RJ, Björklund A (2002) Parkinson-like neurodegeneration induced by targeted overexpression of alpha-synuclein in the nigrostriatal system. J Neurosci 22:2780-2791.

Lee KW, Chen W, Junn E, Im JY, Grosso H, Sonsalla PK, Feng X, Ray N, Fernandez JR, Chao Y, Masliah E, Voronkov M, Braithwaite SP, Stock JB, Mouradian MM (2011) Enhanced phosphatase activity attenuates alpha-Synucleinopathy in a mouse model. J Neurosci 31:6963-6971.

Lee MK, Stirling W, Xu Y, Xu X, Qui D, Mandir AS, Dawson TM, Copeland NG, Jenkins NA, Price DL (2002) Human alpha-synuclein-harboring familial Parkinson's disease-linked Ala-53 $\rightarrow$ Thr mutation causes neurodegenerative disease with alpha-synuclein aggregation in transgenic mice. Proc Natl Acad Sci U S A 99:8968-8973.

Lee VM, Trojanowski JQ (2006) Mechanisms of Parkinson's disease linked to pathological alpha-synuclein: new targets for drug discovery. Neuron 52:33-38.

Lou H, Montoya SE, Alerte TN, Wang J, Wu J, Peng X, Hong CS, Friedrich EE, Mader SA, Pedersen CJ, Marcus BS, McCormack AL, Di Monte DA, Daubner SC, Perez RG (2010) Serine 129 phosphorylation reduces the ability of alpha-synuclein to regulate tyrosine hydroxylase and protein phosphatase 2A in vitro and in vivo. J Biol Chem 285:17648-17661.

Machiya Y, Hara S, Arawaka S, Fukushima S, Sato H, Sakamoto M, Koyama S, Kato T (2010) Phosphorylated alpha-synuclein at Ser-129 is targeted to the proteasome pathway in a ubiquitin-independent manner. J Biol Chem 285:40732-40744.

Maingay M, Romero-Ramos M, Kirik D (2005) Viral vector mediated overexpression of human alpha-synuclein in the nigrostriatal dopaminergic neurons: a new model for Parkinson's disease. CNS Spectr 10:235-244.

Mandel RJ, Spratt SK, Snyder RO, Leff SE (1997) Midbrain injection of recombinant adeno-associated virus encoding rat glial cell line- derived neurotrophic factor protects nigral neurons in a progressive 6-hydroxydopamine-induced degeneration model of Parkinson's disease in rats. Proc Natl Acad Sci U S A 94:14083-14088.

Mbefo MK, Paleologou KE, Boucharaba A, Oueslati A, Schell H, Fournier M, Olschewski D, Yin G, Zweckstetter M, Masliah E, Kahle PJ, Hirling H, Lashuel HA (2010) Phosphorylation of synucleins by members of the Polo-like kinase family. J Biol Chem 285:2807-2822.

McFarland NR, Fan Z, Xu K, Schwarzschild MA, Feany MB, Hyman BT, McLean PJ (2009) Alpha-synuclein S129 phosphorylation mutants do not alter nigrostriatal toxicity in a rat model of Parkinson disease. J Neuropathol Exp Neurol 68:515-524.

Michell AW, Tofaris GK, Gossage H, Tyers P, Spillantini MG, Barker RA (2007) The effect of truncated human alpha-synuclein (1-120) on dopaminergic cells in a transgenic mouse model of Parkinson's disease. Cell Transplant 16:461-474.

Niwa H, Yamamura K, Miyazaki J (1991) Efficient selection for high-expression transfectants with a novel eukaryotic vector. Gene 108:193-199.

Okochi M, Walter J, Koyama A, Nakajo S, Baba M, Iwatsubo T, Meijer L, Kahle PJ, Haass C (2000) Constitutive phosphorylation of the Parkinson's disease associated alpha-synuclein. J Biol Chem 275:390-397.

Paleologou KE, Schmid AW, Rospigliosi CC, Kim HY, Lamberto GR, Fredenburg RA, Lansbury PT Jr, Fernandez CO, Eliezer D, Zweckstetter M, Lashuel HA (2008) Phosphorylation at Ser-129 but not the phosphomimics S129E/D inhibits the fibrillation of alpha-synuclein. J Biol Chem 283:16895-16905.

Paxinos G, Watson C (2007) The rat brain in stereotaxic coordinates, Ed 6 . San Diego: Elsevier Academic.

Pronin AN, Morris AJ, Surguchov A, Benovic JL (2000) Synucleins are a novel class of substrates for $G$ protein-coupled receptor kinases. J Biol Chem 275:26515-26522.

Sakamoto M, Arawaka S, Hara S, Sato H, Cui C, Machiya Y, Koyama S, Wada M, Kawanami T, Kurita K, Kato T (2009) Contribution of endogenous G-protein-coupled receptor kinases to Ser 129 phosphorylation of alphasynuclein in HEK293 cells. Biochem Biophys Res Commun 384:378-382.

Sauer H, Rosenblad C, Björklund A (1995) Glial cell line-derived neurotrophic factor but not transforming growth factor beta 3 prevents delayed degeneration of nigral dopaminergic neurons following striatal 6-hydroxydopamine lesion. Proc Natl Acad Sci U S A 92:8935-8939.

Spillantini MG, Schmidt ML, Lee VM, Trojanowski JQ, Jakes R, Goedert M (1997) Alpha-synuclein in Lewy bodies. Nature 388:839-840.

Spira PJ, Sharpe DM, Halliday G, Cavanagh J, Nicholson GA (2001) Clinical and pathological features of a parkinsonian syndrome in a family with an Ala53Thr alpha-synuclein mutation. Ann Neurol 49:313-319.

Tofaris GK, Razzaq A, Ghetti B, Lilley KS, Spillantini MG (2003) Ubiquitination of alpha-synuclein in Lewy bodies is a pathological event not associated with impairment of proteasome function. J Biol Chem 278:44405-44411.

Volles MJ, Lee SJ, Rochet JC, Shtilerman MD, Ding TT, Kessler JC, Lansbury PT Jr (2001) Vesicle permeabilization by protofibrillar alpha-synuclein: implications for the pathogenesis and treatment of Parkinson's disease. Biochemistry 40:7812-7819.

Willets JM, Challiss RA, Nahorski SR (2002) Endogenous G proteincoupled receptor kinase 6 regulates M3 muscarinic acetylcholine receptor phosphorylation and desensitization in human SH-SY5Y neuroblastoma cells. J Biol Chem 277:15523-15529.

Xu J, Kao SY, Lee FJ, Song W, Jin LW, Yankner BA (2002) Dopaminedependent neurotoxicity of alpha-synuclein: a mechanism for selective neurodegeneration in Parkinson disease. Nat Med 8:600-606.

Zolotukhin S, Byrne BJ, Mason E, Zolotukhin I, Potter M, Chesnut K, Summerford C, Samulski RJ, Muzyczka N (1999) Recombinant adenoassociated virus purification using novel methods improves infectious titer and yield. Gene Ther 6:973-985.

Zolotukhin S, Potter M, Zolotukhin I, Sakai Y, Loiler S, Fraites TJ Jr, Chiodo VA, Phillipsberg T, Muzyczka N, Hauswirth WW, Flotte TR, Byrne BJ, Snyder RO (2002) Production and purification of serotype 1, 2, and 5 recombinant adeno-associated viral vectors. Methods 28:158-167. 